\title{
ORIGINAL \\ DETERMINANTS OF DEPRESSION IN FEMALE ADOLESCENTS AND YOUTH
}

PROF-1324

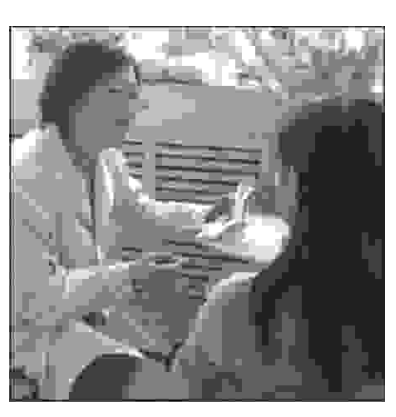

\author{
DR. SAIRA AFZAL \\ MBBS, MCPS (Med) \\ Demonstrator Community Medicine \\ KEMU, Lahore. \\ DR. TASNEEM FATIMA RANA \\ MBBS, MCPS \\ Assistant Professor \\ KEMU, Lahore.
}

\author{
DR. SHAHID MEHMOOD \\ MBBS, FCPS \\ Associate Professor \\ KEMU, Lahore.
}

\begin{abstract}
Introduction: Adolescents and youth are the main human resource for a nation. Depression is a grave yard for hopes and prosperity making the generation sad, inactive, and having suicidal thoughts. Thus every effort should be made to create awareness and eliminate depression from our youth. Objective: To find out the psychosocial determinants of depression in female adolescent and youth. Design: Case control study. Place and duration: Lahore cant urban area, from March, 2007 to July, 2007. Material and methods: It was a community based case control study. Total 400 young females were selected. 200 cases of depression and 200 in the control group. An interview schedule including a structured, pre-tested and bilingual questionnaire was used after taking consent. SPSS and Epi info were used for data analysis. Chi square test was applied. Results: In this study the depression in adolescent and young females had statistically significant relationship with unemployment, underage marriage, early child bearing, infertility, violence, sexual harassment $(p<0.05)$. The family history of psychiatric ill ness in first degree relatives had no statistically significant association with depression in these females $(p>0.05)$. Conclusion: The statistically significant psychosocial determinants of depression in young and adolescent females should be rectified by creating awareness in the society.
\end{abstract}

Key words: Adolescent, youth, depression.

\section{INTRODUCTION}

Pakistan currently has one of the largest cohorts of young people in its history, with approximately twenty five million adolescents and youth between the ages of 15 and $24^{1}$. Adolescents and youth are the present resource and future leadership of Pakistan as they are important for social, political, and economical development and stability of the country. National programs aimed at addressing adolescents and youth tend to be narrowly defined and based either on policies 
developed by the Ministry of Women's Affairs or on programs implemented by the Ministry of Education and Youth Affairs Division". These programs have largely been formulated as a reaction to problems related to young people, such as child labor, low levels of education and malnutrition .e.g. in a national study it is observed that $48.2 \%$ of working adolescents never enrolled in school and $31 \%$ adolescent females and $66 \%$ males were physically abused ${ }^{2}$. Depression in adolescents involves more social and interpersonal difficulties which directly lead to self-esteem problems. Adolescents are more likely to idealize suicide as a solution to feelings of helplessness. Researchers found that depressed adolescents developed in depressed adults having serious social adjustment problems ${ }^{3}$. Adolescents socially isolate themselves when depressed out of feelings of guilt. Dramatic behaviors such as aggression and an obsession or fascination with death often accompany their depression. Adolescent problems that correlate with low self-esteem include depression, unsafe sex, criminal activity, and drug abuse. The suicide rate in teenagers has quadrupled in the last quarter century making it the 3rd leading cause of adolescent death in the USA ${ }^{4}$. In Utah, it is the number one cause of death for individuals $15-25$ years. $A$ high school with a population of 2,000 students can expect 50 attempted suicides per year ${ }^{4}$. And yet adolescent and youth depression and other affective disorders continue to be an area primarily ignored by the parents, teachers and health care providers ${ }^{5}$. Many studies have documented the fact that females are more predisposed to depression, suicidal thoughts and suicide attempts than are males. For example, roughly 1 in 10 adolescent females report engaging in some form of suicide attempt, while 1 in 25 adolescent males report doing the same ${ }^{6}$. Thus there is a dire need to find out the factors causing depression in young females.

Young people are facing life with critical decisions about themselves, their families and their community because they are under going a transition to adulthood with more responsibilities towards their society. If an adolescent or youth has depression this will lead to economic burden to himself, the family as well as the country. Although many studies have been done on education and nutritional aspects but no study on depression in this age group has been done in Pakistan.

The purpose of the study was to find out the determinants of depression in females of this most productive age including unemployment, under age marriages, early child bearing, infertility, physical violence, sexual harassment and psychiatric family history in first degree relatives.

In our society there are various social taboos and gender role variations restricting females to discuss their issues like depression. As the females enter in puberty the out side world become limited and opportunities get reduced to them due to gender discrimination and social pressures. The efforts and decisions made to improve the lives of adolescent and young females are mainly influenced by their home environment, social attitudes and family experiences. Thus this study was a bold step to provide us the insight in the real problems faced by our young females in our society, thereby providing the government, non-governmental organizations, donars and other partners working for the prosperity of the nation with the evidence needed to develop appropriate policies and programs that should address the unique and diverse needs of Pakistani young females to make their lives better.

\section{MATERIAL AND METHOD}

It was a community based case control study done in Loni Mandi Sadar Lahore cant, where a sizeable majority comprised of middle-lower socioeconomic class having monthly income less than Rs 10,000. In our study following operational definitions are used:

Depression is defined as episodes of unexpected sad mood more than 2 weeks and suicidal thoughts. Adolescent is defined as 15-19 years of age. Youth is defined as 20-25 years of age. Under age marriage is defined as marriage before $18 \mathrm{yrs}$. Early child bearing is defined as pregnancy before 18 years. Infertility is defined as having no child for two years after marriage with out any contraceptive method. Violence and sexual 
harassment is defined as offensive behavior or action of physical or sexual abuse.

The area which was surveyed was comprised of more than 1500 housing units. 1000 families were approached within the community and 235 cases of depression in female adolescent and youth were identified. Thirty five were excluded due to the exclusion criteria. Thus 200 were the cases of depression in adolescent and young females in our study. Females in same age group and socioeconomic class who do not have the symptoms of depression were selected as control group. Thus total 400 young females were selected for the study. The included females were 15-25 years old. Those who were diagnosed cases of depression and taking anti depressants were also included in the study. Any female having chronic illness or addiction was excluded from the study. In this study depression in female adolescent and youth was a dependent variable and independent variables were unemployment, underage marriage, early child bearing, infertility, violence, sexual harassment, family history of psychiatric illness in first degree relatives. Duration of the study was from March, 2007 to July, 2007.

An interview schedule was designed to collect information about determinants of depression. A pretested, structured and bilingual questionnaire was used after taking consent and all information was kept confidential.

SPSS version 13 and Epi-info were used for data analysis. Chi-square test was applied to the data.

\section{RESULTS}

Out of total 400 adolescent and young females, two hundred and forty were the unemployed or non-working ladies while one hundred and sixty were the employed or working ladies. Depression was more in non-working ladies i.e. $40 \%$ in unemployed females as compared to $10 \%$ in working ladies. (Tablel) Significant relationship was present between unemployment and depression in females. $(p<0.05)$.

\begin{tabular}{|l|c|c|c|c|c|}
\hline \multicolumn{5}{|c|}{ Table-I. Distribution of determinants in two groups } \\
\hline \multicolumn{1}{|c|}{ Determinant } & \multicolumn{2}{c|}{ Depression } & \multicolumn{2}{c|}{ No depression } & Total \\
\hline Unemployed & 160 & $40 \%$ & 80 & $20 \%$ & $60 \%$ \\
\hline Employed & 40 & $10 \%$ & 120 & $30 \%$ & $40 \%$ \\
\hline Under age marriage & 80 & $20 \%$ & 40 & $10 \%$ & $30 \%$ \\
\hline Others & 120 & $30 \%$ & 160 & $40 \%$ & $70 \%$ \\
\hline Early child birth & 80 & $20 \%$ & 40 & $10 \%$ & $30 \%$ \\
\hline Others & 120 & $30 \%$ & 160 & $40 \%$ & $70 \%$ \\
\hline Infertility & 32 & $8 \%$ & 8 & $2 \%$ & $10 \%$ \\
\hline Others & 168 & $42 \%$ & 192 & $48 \%$ & $90 \%$ \\
\hline $\begin{array}{l}\text { Violence and sexual } \\
\text { harassment }\end{array}$ & 40 & $10 \%$ & 8 & $2 \%$ & $12 \%$ \\
\hline Others & 160 & $40 \%$ & 192 & $48 \%$ & $88 \%$ \\
\hline Psychiatric family history & 16 & $4 \%$ & 8 & $2 \%$ & $6 \%$ \\
\hline Others & 184 & $46 \%$ & 192 & $48 \%$ & $94 \%$ \\
\hline
\end{tabular}


One hundred and twenty females had been the victim of under age marriages (30\%) and depression was present in $20 \%$ of these females. Others included unmarried females and those who got married after $18 \mathrm{yrs}$ of age $(70 \%)$. Depression was $30 \%$ in them (Table I). Thus a significant relationship was found between under age marriages and depression in adolescent and young females. $(p=0.0000127)$ (Table II).

Depression was present in eighty females having early child bearing as compared to forty females who had no depression in the same situation. $(20 \%$ and $10 \%$ respectively).

Table-II. Odd's ratio (OR), $95 \%$ confidence interval(CI), Chi-square and $\mathrm{p}$ value of the determinants of depression.

\begin{tabular}{|c|c|c|c|c|}
\hline Determinants & OR & $95 \% \mathrm{Cl}$ & Chi-square & $p$-value \\
\hline Unemployment & 0.17 & $0.1-0.27$ & 66.67 & $<0.05$ \\
\hline Under age marriages & 2.67 & $1.67-4.28$ & 19.05 & $<0.05$ \\
\hline Early child birth & 2.67 & $1.67-4.28$ & 19.05 & $<0.05$ \\
\hline Infertility & 4.57 & $1.95-11.09$ & 16 & $<0.05$ \\
\hline Violence and sexual harassment & 6 & $2.61-14.33$ & 24 & $<0.05$ \\
\hline Psychiatric family history & 2.09 & $0.82-5.46$ & 2.84 & $>0.05$ \\
\hline
\end{tabular}

Others included females having no child and those who were older than $18 \mathrm{yrs}$ and have children. Among them $30 \%$ had depression.(Table I). Thus a significant relationship was present between early child bearing and depression. $(p<0.05)$ (Table II).

In forty females (10\%) infertility was present and thirty two were depressed (8\%) as compared to eight females $(2 \%)$ who were not depressed. (Table I). Thus a significant relationship was present. $(p=0.00006)$ (Table II).

In the study forty eight females were the victim of violence and sexual harassment. (12\%). Forty were depressed while eight had no depression. (10\% and $2 \%)$. (Tablel) Significant relationship was found. $(p=0.000)$. (Table II).

Family history of psychiatric illness was present in twenty four females and sixteen had depression(4\%). No significant relationship was found. (Tablell).

\section{DISCUSSION}

According to international researchers about $5 \%$ of adolescents suffer from depression symptoms such as persistent sadness, falling academic performance and a lack of interest in previously enjoyable tasks ${ }^{7}$. In our study $15.8 \%$ of adolescent and young females in middle lower socioeconomic class had depression. In international research, depression is considered when symptoms such as suicidal thoughts and loss of interest in social activities for a period of at least two weeks is present $^{8}$. In our study we have considered the same parameters to identify the cases of depression. In many researches depression is found more in middle-lower socioeconomic class $^{9}$ thus we have approached this class in our study. In our study employed or working females are having less depression as compared to nonworking. $(p<0.05)$. This difference is due to the fact that they are more independent economically and they have more creative work to perform. Our results are same as in international studies on this issue ${ }^{10}$.

In another study, under age marriage was discussed as a constant source of frustration and depression. A study 
done in Gaza revealed that $30 \%$ of female married minors contemplated suicide due to depression ${ }^{11}$. In our study significant relationship was found between depression and under age marriages. $(p<0.05)$. Under age marriages also increase the risk of early child bearing and according to our study a significant association was present between depression in adolescent and female youth and early child bearing. $(p<0.05)$.

Some authors have paid attention to the fact that symptoms of depression like health problems, loss of self-esteem, feeling sad, threat, sexual distress, guilt, anxiety, frustration, emotional distress and marital problems are all associated with infertility ${ }^{12}$. We found a significant relationship between depression in young females and infertility in our study. $(p<0.05)$.

In our study $12 \%$ females were the victim of physical violence and sexual harassment and statistically significant adolescent and young females had depression in this group. $(p=0.000)$. In an international study on females, a self-report of sexual abuse was found to be independently associated with suicidal ideation, suicide attempts, other forms of self-injury, depression, feelings of hopelessness and family dysfunction. Females with high levels of distress associated with sexual abuse had roughly three times the risk of depression. More than half of the sexually abused males $(55 \%)$ and nearly a third $(29 \%)$ of the sexually abused females attempted suicide due to depression ${ }^{13}$.

Although genetic factors and family history are blamed for depression in most of the research works but in our study no significant relationship was found ${ }^{14}$. This is due to the fact that restricted environment and social atmosphere in our country had more bad effect on the mental health of the females than on males with more freedom of thoughts and movement. The genetics was not significant in female depression in our society.

Depression can lead to serious short and long term problems including a breakdown in family and personal relationships as well as poor academic and work performance $^{15}$. Moreover depression has also been linked to alcohol and drug abuse, eating disorders, and implicated in cases of youth suicide ${ }^{16}$. The extent and magnitude of the mental health problem in adolescent is not fully known and require intensive and extensive investigation so I recommend for other researchers to explore these aspects in adolescent and youth in Pakistan which are still unrevealed.

\section{CONCLUSION}

The study would help to create awareness among health professionals to understand the major determinants of depression in young females, and the most appropriate way of policy making to solve the problems like unemployment, under age marriages, early child birth, infertility, physical violence and sexual harassment so that our females could actively participate in national development.

\section{REFERENCES}

1. Cythia B L, Judith AD, Monica G, Zeba A S, Minhaj H, Azeema $F$ et al. Adolescents and youth in Pakistan. 2001-02; a nationally representative survey. Islamabad: Population Council; 2002; 1-6.

2. Aliya HK, Lubna S. Trade off patterns between working and education of Adolescents: Evidence from PIHS 1998-99; Pakistan's population stabilization prospects, $2^{\text {nd }}$ conference proceedings. Islamabad: Population Association Pakistan;2001;207-10.

3. Yehudi R. Post traumatic stress disorder. New England Journal of Medicine 2002;346:108-114.

4. Watson JP, Davis T. ABC of mental health: psychosexual problems. British Medical Journal 1997;315: 239-242.

5. Mayo-Smith MF. Pharmacological management of depression: a meta-analysis and evidence based practice guideline. Journal of American Medical Association 1997;278:144-151.

6. William $H$, Salter $M$, Ghodse AH. Management of substance misusers due to depression on the general hospital ward. British Journal of Clinical Practice 1996; 50: $94-98$. 
7. Daly I. Mania. Lancet 1997;349: 1157-60.

8. Henry JA. Suicidal risk and antidepressant treatment. Journal of psychopharmacology 1996; 19: 39-40.

9. Mc Guffin P, Nelson M. Science, medicine and the future: behaviour and genes. British Medical Journal 1999; 319: 37-40.

10. Yen, I. H. \& Kaplan, G. A. Poverty area residence and changes in depression and perceived health status: evidence from the Alameda County Study. Int.J. Epidemiol 1999; 28: 90-94.

11. Beekman, A. T. Deeg, D. J. Braam, A. W. Smit, J. Van Tilburg, W. Consequences of major and minor depression in later life: a study of disability, wellbeing and service utilization. Psychol.Med 1997; 27: 1397-1409.

12. Edelmann RG, Connolly KJ. Psychological consequences of infertility. Brit $J$ Med Psychol. 1985;59:202-19.
13. Brand, E., King, C., Olson, E., Ghaziuddin, N. \& Naylor, M. Depressed adolescents with a history of sexual abuse: diagnostic comorbidity and suicidality. Journal of the American Academy of Child and Adolescent Psychiatry, 1996; 35: 34-42.

14. Allen, J., Hauser, S., Eickholt, C., Bell, K. \& O'Connor, T. (1994). Autonomy and relatedness in family interactions as predictors of expressions of negative adolescent affect. Journal of Research on Aolescence 1994; 4: 535-552.

15. Davila, J., Hammen, C., Burge, D., Paley, B., \& Daley, S. Poor interpersonal problem solving as a mechanism of stress generation in depression among adolescent women. Journal of Abnormal Psychology 1995; 104:592601.

16. Lamarine, R. Child and adolescent depression. Journal of School Health 1995; 65: 390-394.

\section{URO-PREGNANCY CARD \\ \# 03 URO - PREGNANCY \\ SAJIDAASGHAR $27 Y$ \\ W/O MUHAMMAD ASGHAR \\ WARD NO. 4 MOGHAL HOUSE. \\ SANGLAHILL \\ LMP Dec-05 \\ EDD Sep=06 \\ - Free consultation by medical officers \\ - 24 hours service throughout the year \\ - Emergency services \\ - $100 \%$ discount on medical officer fee on hospitalization

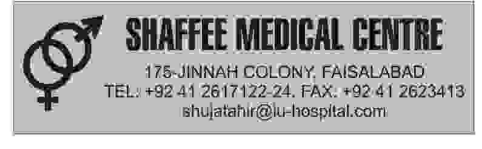

